\title{
Effects of Dietary Histidine on Growth Performance, Serum Amino Acids, and Intestinal Morphology and Microbiota Communities in Low Protein Diet-Fed Piglets
}

\author{
Meng Kang, ${ }^{1}$ Jie Yin $\mathbb{D}^{1}{ }^{1}$ Jie Ma, ${ }^{1}$ Xin Wu, ${ }^{1}$ Ke Huang, ${ }^{1}$ Tiejun $\mathrm{Li}^{2}$ and Long Ouyang ${ }^{3}$ \\ ${ }^{1}$ College of Animal Science and Technology, Hunan Agricultural University, Changsha, China \\ ${ }^{2}$ Key Laboratory of Agro-ecological Processes in Subtropical Region, Institute of Subtropical Agriculture, Chinese Academy of Sciences; \\ Scientific Observing and Experimental Station of Animal Nutrition and Feed Science in South-Central, Ministry of Agriculture; \\ Hunan Provincial Engineering Research Center for Healthy Livestock and Poultry Production, Hunan, China \\ ${ }^{3}$ Hunan Provincial Veterinary Drug and Feed Supervision Institute, Changsha, China
}

Correspondence should be addressed to Jie Yin; yinjie2014@126.com

Received 13 June 2020; Revised 8 October 2020; Accepted 19 October 2020; Published 28 November 2020

Academic Editor: Miaomiao Wu

Copyright (C) 2020 Meng Kang et al. This is an open access article distributed under the Creative Commons Attribution License, which permits unrestricted use, distribution, and reproduction in any medium, provided the original work is properly cited.

\begin{abstract}
Previous study showed that low protein diet-fed pigs are characterized by lower histidine concentration in the serum and muscle, suggesting that histidine may involve in protein-restricted response. Thus, the current study mainly investigated the effects of dietary histidine on growth performance, blood biochemical parameters and amino acids, intestinal morphology, and microbiota communities in low protein diet-challenged-piglets. The results showed that protein restriction inhibited growth performance, blood biochemical parameters and amino acids, and gut microbiota but had little effect on intestinal morphology. Dietary supplementation with histidine markedly enhanced serum histidine level and restored tryptophan concentration in low protein diet-fed piglets, while growth performance and intestinal morphology were not markedly altered in histidine-treated piglets. In addition, histidine exposure failed to affect bacterial diversity (observed species, Shannon, Simpson, Chao1, ACE, and phylogenetic diversity), but histidine-treated piglets exhibited higher abundances of Butyrivibrio and Bacteroides compared with the control and protein-restricted piglets. In conclusion, dietary histidine in low protein diet enhanced histidine concentration and affected gut microbiota (Butyrivibrio and Bacteroides) but failed to improve growth performance and intestinal morphology.
\end{abstract}

\section{Introduction}

Low protein diet has been widely used in pig industry to save protein sources and alleviate the nitrogen excretion [1]. Covering amino acid requirements maintains the growth performance in proper low protein diet-fed pigs [2]. For example, we found that reducing $3 \%$ dietary crude protein and balancing lysine, methionine, threonine, and tryptophan fails to markedly affect feed intake and weight gain from weaning piglets to finishing pigs, while $6 \%$ protein limitation causes a significant reduction in growth performance [3]. Also, low protein diet has been reported to enhance meat quality of growing and finishing pigs by targeting lipid metabolism, fiber characteristics, and amino acid metabolism in the muscle tissue [4]. Meanwhile, protein restriction in other animal models also shows many merits, such as improving healthy lifespan and reducing tumor incidence $[5,6]$. The potential mechanism may be associated with amino acid metabolic programming, while amino acid metabolic response and the requirement in protein-restricted models have not been fully study.

Our previous study revealed a marked change in amino acid metabolism in low protein diet-fed pigs, especially for reduction in histidine and branched-chain amino acids [3]. Zhang et al. reported that dietary supplementation with branched-chain amino acids increases growth performance and muscle mass in low protein diet-challenged piglets [7]. However, little study has focused on the role of histidine in protein-restricted piglets. In addition, histidine deficiency in diet shows a negative relationship with lactational performance in dairy cows [8]. Furthermore, dietary $0.18 \%$ 
TABLE 1: Effect of dietary histidine on growth performance in low protein diet-fed piglets.

\begin{tabular}{|c|c|c|c|c|c|}
\hline Item & Control group & Low protein group & Histidine group & Sem & $P$ value \\
\hline Initial body weight $(\mathrm{kg})$ & 7.69 & 7.64 & 7.68 & 0.17 & 0.99 \\
\hline Final body weight $(\mathrm{kg})$ & $21.53^{\mathrm{a}}$ & $16.86^{\mathrm{b}}$ & $16.51^{\mathrm{b}}$ & 0.69 & $<0.01$ \\
\hline Average daily weight gain $(\mathrm{kg})$ & $0.39^{\mathrm{a}}$ & $0.26^{\mathrm{b}}$ & $0.25^{\mathrm{b}}$ & 0.02 & $<0.01$ \\
\hline \multicolumn{6}{|l|}{ Average daily feed intake $(\mathrm{kg})$} \\
\hline Week 1 & 0.42 & 0.41 & 0.39 & 0.01 & 0.18 \\
\hline Week 2 & 0.66 & 0.64 & 0.53 & 0.03 & 0.16 \\
\hline Week 3 & 0.61 & 0.51 & 0.54 & 0.04 & 0.51 \\
\hline Week 4 & $0.63^{\mathrm{a}}$ & $0.47^{\mathrm{b}}$ & $0.45^{\mathrm{b}}$ & 0.03 & $<0.01$ \\
\hline Week 5 & $0.94^{\mathrm{a}}$ & $0.64^{\mathrm{b}}$ & $0.63^{\mathrm{b}}$ & 0.04 & $<0.01$ \\
\hline Week 6 & $0.85^{\mathrm{ab}}$ & $0.69^{\mathrm{b}}$ & $0.87^{\mathrm{a}}$ & 0.04 & 0.08 \\
\hline Week 7 & $1.11^{\mathrm{a}}$ & $0.75^{\mathrm{b}}$ & $0.80^{\mathrm{b}}$ & 0.05 & $<0.01$ \\
\hline
\end{tabular}

${ }^{\mathrm{a}, \mathrm{b}}$ Within a row means the difference was significant with different superscripts $(P<0.05)$.

histidine improves muscle and blood 1,1-diphenyl-2-picrylhydrazyl radical scavenging capacity in turkey [9]. Thus, this study mainly investigated the effect of histidine on low protein diet-fed piglets with focuses on growth performance, serum amino acid profiles, and gut microbiota communities.

\section{Materials and Methods}

2.1. Animals and Groups. 24 piglets (Landracexlarge white, gibbed male, and $7.678 \pm 0.17 \mathrm{~kg}$ body weight) were randomly divided into 3 groups $(n=8)$ : a control group $(17 \%$ $\mathrm{CP})$, a low protein group ( $14 \% \mathrm{CP})$, and a low protein group supplemented with $0.1 \%$ histidine to keep the same concentration compared with the control diet. Data from the control and low protein groups shared with our previous study [10]. Animals were housed individually and given fresh feed 3 times per day for 35 days. At the end of each period, all piglets were killed for sample collection. Experimental protocol of piglet study was approved by the Animal Care and Use Committee of Institute of Subtropical Agriculture, Chinese Academy of Sciences.

2.2. Growth Performance. Feed intake and body weight from each animal were recorded. The liver, kidney, and spleen indexes were also calculated according to the ratio to the body weight of piglet.

2.3. Blood Biochemical Parameters. Blood samples were harvested from anterior vena cava and centrifugated $(3000 \mathrm{rpm}$, $10 \mathrm{~min}$, and $4^{\circ} \mathrm{C}$ ) for serum collection. Biochemical kits for total protein (TP), albumin (ALB), alanine aminotransferase (ALT), aspartate aminotransferase (AST), alkaline phosphatase (ALP), urea nitrogen (BUN), creatinine (CREA), glucose (Glu), Creactive protein (CERL3), bile acid (BILT3), and immunoglobulin G (IGG) were purchased from Roche (Shanghai, China) and tested by the Cobas c-311 coulter chemistry analyzer [3].

2.4. Blood Sample Preparation and Amino Acid Determination. 18 amino acids in the serum were determined via a High-speed Amino Acid Analyzer L-8900 (Japan).
2.5. Intestinal Histological Examination. Middle sections of the jejunum and ileum from all animals were fixed with $4 \%$ paraformaldehyde-PBS and then dehydrated and embedded in paraffin blocks for H\&E dyeing. Villus length, crypt depth, and villus surface area were measured.

2.6. Gut Microbiota Sequencing. Total genome DNA from distal intestinal digesta samples was extracted for amplification using specific primer with the barcode (16S V3+4). Sequencing libraries were generated and analyzed according to our previous study [11]. Subsequent analysis of alpha diversity (Observed-species, Chao1, Shannon, and Simpson) was performed basing on this output normalized data.

2.7. Statistical Analysis. Statistical analysis of all data was performed using the one-way analysis of variance (ANOVA) to test homogeneity of variances via Levene's test and followed with Duncan's test (IBM SPSS 23 software). Data are expressed as the mean. Values in the same row with different superscripts are significant $(P<0.05)$.

\section{Results}

3.1. Effect of Dietary Histidine on Growth Performance in Low Protein Diet-Fed Piglets. Final body weight, average daily weight gain, and average daily feed intake in each week during the experiment were analyzed, and the results showed that reducing dietary CP markedly reduced final body weight and average daily weight gain $(P<0.05)$, while dietary supplementation with histidine failed to improve body weight gain $(P>0.05)$. Feed intake was not altered at weeks 1-3, but low protein diet reduced feed intake from week 4 to week $7 \quad(P<0.05)$. Interestingly, dietary histidine markedly improved average feed intake at week $6(P<0.05)$ but had no effect in other weeks (Table 1).

3.2. Effect of Dietary Histidine on Relative Organ Weight in Low Protein Diet-Fed Piglets. The relative weights of the liver, kidney, and spleen were calculated, and the results showed that the liver relative weight was markedly increased and the kidney relative weight was reduced in the low protein group $(P<0.05)$, while histidine supplementation failed to 
TABLE 2: Effect of dietary histidine on relative organ weight in low protein diet-fed piglets.

\begin{tabular}{lccccc}
\hline Item & Control group & Low protein group & Histidine group & Sem & $P$ value \\
\hline Liver & $2.71^{\mathrm{b}}$ & $3.00^{\mathrm{a}}$ & $3.05^{\mathrm{a}}$ & 0.06 & 0.05 \\
Kidney & $0.53^{\mathrm{a}}$ & $0.45^{\mathrm{b}}$ & $0.49^{\mathrm{b}}$ & 0.01 & $<0.01$ \\
Spleen & 0.19 & 0.20 & 0.21 & 0.01 & 0.55 \\
\hline
\end{tabular}

${ }^{\mathrm{a}, \mathrm{b}}$ Within a row means the difference was significant with different superscripts $(P<0.05)$.

TABLE 3: Effect of dietary histidine on serum biochemical indexes in low protein diet-fed piglets.

\begin{tabular}{|c|c|c|c|c|c|}
\hline Item & Control group & Low protein group & Histidine group & Sem & $P$ value \\
\hline Total protein & 55.43 & 54.59 & 52.95 & 0.89 & 0.52 \\
\hline Albumin & $39.69^{\mathrm{a}}$ & $37.23^{\mathrm{ab}}$ & $33.99^{\mathrm{b}}$ & 0.82 & 0.01 \\
\hline Alanine aminotransferase & $60.44^{\mathrm{b}}$ & $78.60^{\mathrm{a}}$ & $75.20^{\mathrm{a}}$ & 2.90 & 0.02 \\
\hline Aspartate aminotransferase & 72.43 & 62.25 & 69.13 & 3.28 & 0.46 \\
\hline Alkaline phosphatase & 291.86 & 263.50 & 269.00 & 8.97 & 0.43 \\
\hline Gamma glutamyl transpeptidase & 46.50 & 40.00 & 44.63 & 1.79 & 0.34 \\
\hline Lactate dehydrogenase & $923.38^{\mathrm{a}}$ & $722.38^{\mathrm{b}}$ & $733.50^{\mathrm{b}}$ & 34.76 & 0.02 \\
\hline Acid phosphatase & 18.52 & 20.15 & 18.28 & 1.61 & 0.89 \\
\hline NH3L & 287.80 & 295.36 & 275.86 & 16.56 & 0.89 \\
\hline Immunoglobulin $\mathrm{M}$ & 0.31 & 0.26 & 0.29 & 0.01 & 0.26 \\
\hline Cholinesterase & 711.75 & 727.50 & 672.75 & 20.22 & 0.54 \\
\hline
\end{tabular}

${ }_{\mathrm{a}, \mathrm{b}}$ Within a row means the difference was significant with different superscripts $(P<0.05)$.

affect the liver and kidney weights $(P>0.05)$. Meanwhile, the relative weight of the spleen was not significantly affected in this study (Table 2).

\subsection{Effect of Dietary Histidine on Serum Biochemical Indexes in Low Protein Diet-Fed Piglets. Results of serum biochemical indexes were shown in Table 3. Compared with the control group, serum alanine aminotransferase activity was markedly enhanced, and lactate dehydrogenase activity was reduced in the low protein group $(P<0.05)$. Although histidine expo- sure failed to alleviate the changes of alanine aminotransfer- ase and lactate dehydrogenase activities, albumin abundance was markedly reduced in the histidine-supplemented group compared with that in the control $(P<0.05)$.}

3.4. Effect of Dietary Histidine on Serum Amino Acid Pool in Low Protein Diet-Fed Piglets. Compared with the control group, serine, threonine, alanine, lysine, methionine, and tryptophan were markedly increased, and valine and isoleucine abundances were reduced in low protein diet-fed piglets $(P<0.05)$ (Table 4). Histidine supplementation markedly enhanced histidine and reversed tryptophan concentration $(P<0.05)$. Meanwhile, histidine tended to reversed the changes of methionine and valine, but the difference was insignificant $(P>0.05)$.

3.5. Effect of Dietary Histidine on Intestinal Morphology in Low Protein Diet-Fed Piglets. In the jejunum, piglets from the low protein group showed impaired intestinal morphology evidenced by the decreased trend of villus length, the ratio of villus to crypt depth, and villus surface area, which were slightly improved in the histidine treated group, but all these indexes were insignificant $(P>0.05)$ (Table 5).

In the ileum, villus length was significantly reduced in low protein diet-fed piglets $(P<0.05)$, while dietary supplementation with histidine failed to affect villus length and other morphologic indexes $(P>0.05)$ (Table 5).

3.6. Effect of Dietary Histidine on $\alpha$-Diversity and Gut Microbiota Compositions in Low Protein Diet-Fed Piglets. Observed species, Shannon, Simpson, Chao1, ACE, and phylogenetic diversity were analyzed to evaluate the $\alpha$-diversity of gut microbiota, while all of them were not markedly differentiated between three groups (Table 6), indicating that protein restriction and histidine treatment had little effect on $\alpha$-diversity of gut microbiota in the current study.

Microbiota compositions at the phylum and genus levels were analyzed (Table 7). At the phylum level, Firmicutes and Bacteroidetes were two major bacteria and occupied up to $40 \%$, but all of them were not markedly changed in response to low protein diet and histidine supplementation $(P>0.05)$. The relative abundance of Spirochaetes was markedly increased in low protein diet-fed piglets $(P<0.05)$ but not altered at the histidine group $(P>0.05)$. In addition, Proteobacteria, Melainabacteria, and Tenericutes were also tested at the ileum, but we failed to notice any significant difference between three groups.

At the genus level, Succinivibrio, Anaerovibrio, Faecalibacterium, Alloprevotella, Lactobacillus, Butyrivibrio, Roseburia, Parabacteroides, Subdoligranulum, Oribacterium, Oscillospira, Streptococcus, Fournierella, Bacteroides, and Sphaerochaeta were identified. Compared with the control group, the relative abundances of Subdoligranulum and 
TABLE 4: Effect of dietary histidine on serum amino acid pool in low protein diet-fed piglets.

\begin{tabular}{|c|c|c|c|c|c|}
\hline Item & Control group & Low protein group & Histidine group & Sem & $P$ value \\
\hline Histidine & $2.32^{\mathrm{ab}}$ & $2.04^{\mathrm{b}}$ & $2.82^{\mathrm{a}}$ & 0.13 & 0.05 \\
\hline Serine & $15.21^{\mathrm{b}}$ & $20.59^{\mathrm{a}}$ & $19.61^{\mathrm{a}}$ & 0.74 & $<0.01$ \\
\hline Arginine & 29.77 & 28.10 & 27.47 & 0.99 & 0.64 \\
\hline Glycine & 115.42 & 103.13 & 100.51 & 3.64 & 0.20 \\
\hline Aspartic acid & 3.46 & 2.76 & 2.65 & 0.18 & 0.14 \\
\hline Glutamic acid & 66.34 & 61.76 & 57.20 & 2.73 & 0.41 \\
\hline Threonine & $22.90^{\mathrm{b}}$ & $95.46^{\mathrm{a}}$ & $94.13^{\mathrm{a}}$ & 9.61 & $<0.01$ \\
\hline Alanine & $80.23^{\mathrm{b}}$ & $109.29^{\mathrm{a}}$ & $104.04^{\mathrm{a}}$ & 5.15 & 0.04 \\
\hline Proline & 34.44 & 37.20 & 37.87 & 1.53 & 0.63 \\
\hline Cysteine & 0.79 & 0.59 & 0.74 & 0.08 & 0.56 \\
\hline Lysine & $42.97^{\mathrm{b}}$ & $81.43^{\mathrm{a}}$ & $77.76^{\mathrm{a}}$ & 5.61 & $<0.01$ \\
\hline Tyrosine & 15.40 & 14.42 & 14.43 & 0.51 & 0.70 \\
\hline Methionine & $15.22^{\mathrm{b}}$ & $21.83^{\mathrm{a}}$ & $17.06^{\mathrm{ab}}$ & 1.30 & 0.09 \\
\hline Valine & $10.95^{\mathrm{a}}$ & $8.51^{\mathrm{b}}$ & $9.52^{\mathrm{ab}}$ & 0.41 & 0.05 \\
\hline Isoleucine & $12.44^{\mathrm{a}}$ & $4.30^{\mathrm{b}}$ & $5.21^{\mathrm{b}}$ & 0.85 & $<0.01$ \\
\hline Leucine & 19.80 & 18.19 & 18.04 & 0.63 & 0.47 \\
\hline Phenylalanine & 10.47 & 10.85 & 11.13 & 0.28 & 0.64 \\
\hline Tryptophan & $11.47^{\mathrm{b}}$ & $14.6^{\mathrm{a}}$ & $11.81^{\mathrm{b}}$ & 0.58 & 0.05 \\
\hline
\end{tabular}

${ }^{\mathrm{a}, \mathrm{b}}$ Within a row means the difference was significant with different superscripts $(P<0.05)$.

TABLE 5: Effect of dietary histidine on intestinal morphology in low protein diet-fed piglets.

\begin{tabular}{|c|c|c|c|c|c|}
\hline Item & Control group & Low protein group & Histidine group & Sem & $P$ value \\
\hline \multicolumn{6}{|l|}{ Jejunum } \\
\hline Villus length & 513.52 & 469.42 & 542.06 & 14.52 & 0.11 \\
\hline Villus width & 139.61 & 142.18 & 135.31 & 3.77 & 0.76 \\
\hline Crypt depth & 202.84 & 194.10 & 201.17 & 5.40 & 0.80 \\
\hline Villus length/crypt depth & 2.67 & 2.37 & 2.73 & 0.11 & 0.35 \\
\hline Villus surface area $\left(\mathrm{mm}^{2}\right)$ & 0.24 & 0.21 & 0.23 & 0.01 & 0.23 \\
\hline \multicolumn{6}{|l|}{ Ileum } \\
\hline Villus length & $361.30^{\mathrm{a}}$ & $307.13^{\mathrm{b}}$ & $313.07^{\mathrm{b}}$ & 7.72 & $<0.01$ \\
\hline Villus width & 104.52 & 109.24 & 95.82 & 2.73 & 0.08 \\
\hline Crypt depth & 121.09 & 111.34 & 109.65 & 3.95 & 0.52 \\
\hline Villus length/crypt depth & 2.75 & 2.81 & 2.86 & 0.10 & 0.91 \\
\hline Villus surface area $\left(\mathrm{mm}^{2}\right)$ & 0.11 & 0.10 & 0.10 & 0.00 & 0.27 \\
\hline
\end{tabular}

${ }^{\mathrm{a}, \mathrm{b}}$ Within a row means the difference was significant with different superscripts $(P<0.05)$.

Oscillospira were markedly reduced in response to dietary low protein diet $(P<0.05)$, while histidine exposure failed to alleviate the changes of Subdoligranulum and Oscillospira $(P>0.05)$. Interestingly, histidine-treated piglets exhibited higher abundances of Butyrivibrio and Bacteroides compared with the control and protein-restricted subjects $(P<0.05)$.

\section{Discussion}

Previous studies showed that dietary supplementation with amino acids improves growth performance in low protein diet-fed pigs. For example, supplementation of leucine in low protein diet improves protein deposition and meat quality in finishing pigs [12]. Also, the minimum standardized ileal digestible histidine to lysine ratio is suggested to be $28 \%$ in piglets to maintain growth performance by using the curvilinear-plateau model [13]. However, in this study, balancing dietary histidine compared with the control diet failed to affect final body weight and weight gain in pigs, while feed intake at week 6 was markedly enhanced in the histidine group. Furthermore, relative weight of organ and serum biochemical indexes were not altered in response to dietary histidine. The reason may be caused by the dietary dosage and time of histidine, and further studies are suggested to confirm the high histidine and long-term effect on the growth performance in low protein diet-fed piglets.

Our previous study revealed a marked reduction of muscle and serum histidine in low protein diet-fed pigs [3, 14]. 
TABLE 6: Effect of dietary histidine on $\alpha$-diversity of gut microbiota in low protein diet-fed piglets.

\begin{tabular}{|c|c|c|c|c|c|}
\hline Item & Control group & Low protein group & Histidine group & Sem & $P$ value \\
\hline Observed species & 594.88 & 595.75 & 589.00 & 9.43 & 0.96 \\
\hline Shannon & 6.60 & 6.66 & 6.64 & 0.09 & 0.97 \\
\hline Simpson & 0.97 & 0.97 & 0.98 & 0.00 & 0.46 \\
\hline Chaol & 657.03 & 663.29 & 636.86 & 12.81 & 0.70 \\
\hline $\mathrm{ACE}$ & 658.76 & 662.57 & 628.47 & 12.07 & 0.47 \\
\hline Phylogenetic diversity & 45.76 & 45.15 & 45.37 & 0.67 & 0.40 \\
\hline
\end{tabular}

${ }^{\mathrm{a}, \mathrm{b}}$ Within a row means the difference was significant with different superscripts $(P<0.05)$.

TABLE 7: Effect of dietary histidine on gut microbiota compositions in low protein diet-fed piglets.

\begin{tabular}{|c|c|c|c|c|c|}
\hline Item & Control group & Low protein group & Histidine group & Sem & $P$ value \\
\hline \multicolumn{6}{|l|}{ Phylum level (\%) } \\
\hline Firmicutes & 50.53 & 47.44 & 53.30 & 1.26 & 0.17 \\
\hline Bacteroidetes & 43.52 & 41.88 & 38.71 & 1.08 & 0.19 \\
\hline Proteobacteria & 2.45 & 4.38 & 3.72 & 0.61 & 0.44 \\
\hline Spirochaetes & $0.63^{\mathrm{b}}$ & $2.86^{\mathrm{a}}$ & $2.63^{\mathrm{a}}$ & 0.39 & 0.03 \\
\hline Melainabacteria & 0.85 & 0.41 & 0.28 & 0.12 & 0.15 \\
\hline Tenericutes & 0.44 & 0.51 & 0.43 & 0.06 & 0.88 \\
\hline \multicolumn{6}{|l|}{ Genus level (\%) } \\
\hline Succinivibrio & 1.61 & 0.52 & 1.85 & 0.42 & 0.56 \\
\hline Anaerovibrio & 1.72 & 2.20 & 3.98 & 0.75 & 0.45 \\
\hline Faecalibacterium & 2.41 & 1.25 & 1.84 & 0.28 & 0.26 \\
\hline Alloprevotella & 1.84 & 2.38 & 1.55 & 0.31 & 0.54 \\
\hline Lactobacillus & 2.58 & 1.06 & 1.59 & 0.40 & 0.31 \\
\hline Butyrivibrio & $0.01^{\mathrm{b}}$ & $0.05^{\mathrm{b}}$ & $0.56^{\mathrm{a}}$ & 0.11 & 0.06 \\
\hline Roseburia & 0.66 & 1.19 & 0.94 & 0.20 & 0.56 \\
\hline Parabacteroides & 0.52 & 0.83 & 1.05 & 0.11 & 0.11 \\
\hline Subdoligranulum & $1.13^{\mathrm{a}}$ & $0.29^{\mathrm{b}}$ & $0.31^{\mathrm{b}}$ & 0.13 & $<0.01$ \\
\hline Oribacterium & 0.31 & 0.24 & 0.02 & 0.07 & 0.22 \\
\hline Oscillospira & $1.56^{\mathrm{a}}$ & $0.92^{\mathrm{b}}$ & $0.96^{\mathrm{b}}$ & 0.13 & 0.06 \\
\hline Streptococcus & 0.24 & 0.15 & 0.06 & 0.04 & 0.18 \\
\hline Fournierella & 0.83 & 0.40 & 0.39 & 0.10 & 0.10 \\
\hline Bacteroides & $0.09^{\mathrm{b}}$ & $0.27^{\mathrm{b}}$ & $0.74^{\mathrm{a}}$ & 0.10 & 0.02 \\
\hline Sphaerochaeta & 0.39 & 0.84 & 0.50 & 0.11 & 0.24 \\
\hline
\end{tabular}

${ }^{\mathrm{a}, \mathrm{b}}$ Within a row means the difference was significant with different superscripts $(P<0.05)$.

Similarly, serum histidine concentration also tended to decrease in protein-restricted piglets, while balancing histidine in the diet markedly enhanced serum histidine, indicating that dietary supplementation with histidine enhanced intestinal absorption and circulating of histidine. Our previous studies reported that histidine and lysine exhibit competitive inhibitory association in transport and metabolism [11, 15], while dietary histidine in low protein diet failed to markedly inhibit lysine metabolism in the current study. Meanwhile, histidine supplementation markedly reversed tryptophan increase in low protein diet-fed piglets. Dietary tryptophan in pigs has been widely reported to improve growth performance and gut barrier [16, 17]; thus, we speculated the serum tryptophan concentration failed to correlate to growth performance in this study. Together, dietary supplementation with histidine enhanced serum histidine concentration and affected tryptophan metabolism in low protein diet-fed piglets, but the detailed mechanism should be further studied.

Growth performance of piglet is highly associated with intestinal functions (i.e., nutrient digestibility, absorption, and barrier function). Dietary amino acids are mainly used by intestinal epithelial cells to provide energy and form protein molecules $[18,19]$. For example, our previous study showed that dietary supplementation with glutamate markedly improved intestinal morphological structure, intestinal barrier function, and antioxidant system in mycotoxinchallenged pigs [18]. However, dietary histidine slightly improved villus length, the ratio of villus to crypt depth, and villus surface area in the jejunum. Jiang et al. reported 
that histidine supplementation in diets (3.7 up to $12.2 \mathrm{~g} / \mathrm{kg}$ ) blocked $\mathrm{Cu}$-induced decreases in intestinal tight junction proteins and mRNA levels of antioxidant genes [20]. Thus, the effect of histidine on intestinal morphology should be further investigated in different dosages and models.

Dietary changes and supplements are highly associated with gut microbiota, which further affect host metabolism. For example, intestinal bacterial diversity and the relative abundances of Actinobacteria, Saccharibacteria, and Synergistetes at the phylum level were increased in a pig model when feeding a low diet [11]. In addition, gut microbiota alteration contributed to host metabolism, such as energy metabolism, lipid metabolism, and carbohydrate metabolism [21]. In this study, we found that histidine affected tryptophan metabolism, while tryptophan metabolite (melatonin) markedly improved gut microbiota evidenced by increasing bacterial diversity and affecting the relative abundances of Bacteroides and Alistipes in murine model [21]. The current results showed that dietary histidine failed to affect bacterial diversity, but histidine-treated piglets exhibited higher abundances of Butyrivibrio and Bacteroides compared with the control and protein-restricted subjects. Butyrivibrio has been identified in pigs with high residual feed intake [22], indicating that Butyrivibrio may involve in feed intake regulation. Bacteroides species are significant clinical pathogens and are found in most anaerobic infections [23]. However, the mechanism of histidine-mediated Bacteroides proliferation and its role in piglet were not understood in the current study.

In conclusion, low protein diet reduced growth performance and affected serum amino acids and gut microbiota. Dietary supplementation with histidine markedly enhanced serum histidine concentration in low protein diet-fed piglets and restored tryptophan level. In addition, histidinetreated piglets exhibited higher abundances of Butyrivibrio and Bacteroides.

\section{Data Availability}

The data used to support to the findings of this study are available from the corresponding author upon request.

\section{Conflicts of Interest}

The authors declare that they have no competing interests.

\section{Authors' Contributions}

Meng Kang and Jie Yin contributed equally in this work.

\section{Acknowledgments}

This study was supported by the Hunan Science Foundation for Outstanding Young Scholars (2020JJ3023) and the R\&D Program of China (2016YFD0501201).

\section{References}

[1] L. T. Wu, X. Zhang, Z. Tang et al., "Low-protein diets decrease porcine nitrogen excretion but with restrictive effects on amino acid utilization," Journal of Agricultural and Food Chemistry, vol. 66, no. 31, pp. 8262-8271, 2018.

[2] M. Gloaguen, N. le Floc'h, Y. Primot, E. Corrent, and J. van Milgen, "Performance of piglets in response to the standardized ileal digestible phenylalanine and tyrosine supply in low-protein diets," Animal, vol. 8, no. 9, pp. 1412-1419, 2014.

[3] J. Yin, Y. Li, X. Zhu et al., "Effects of long-term protein restriction on meat quality, muscle amino acids, and amino acid transporters in Pigs," Journal of Agricultural and Food Chemistry, vol. 65, no. 42, pp. 9297-9304, 2017.

[4] Y. H. Li, F. N. Li, Y. H. Duan et al., "Low-protein diet improves meat quality of growing and finishing pigs through changing lipid metabolism, fiber characteristics, and free amino acid profile of the muscle," Journal of Animal Science, vol. 96, no. 8, pp. 3221-3232, 2018.

[5] J. Yin, W. Ren, X. Huang, T. Li, and Y. Yin, "Protein restriction and cancer," Biochimica et Biophysica Acta (BBA) - Reviews on Cancer, vol. 1869, no. 2, pp. 256-262, 2018.

[6] H. Mirzaei, J. A. Suarez, and V. D. Longo, "Protein and amino acid restriction, aging and disease: from yeast to humans," Trends in Endocrinology and Metabolism, vol. 25, no. 11, pp. 558-566, 2014.

[7] L. Zheng, H. Wei, C. Cheng, Q. Xiang, J. Pang, and J. Peng, "Supplementation of branched-chain amino acids to a reduced-protein diet improves growth performance in piglets: involvement of increased feed intake and direct muscle growth-promoting effect," The British Journal of Nutrition, vol. 115, no. 12, pp. 2236-2245, 2016.

[8] F. Giallongo, M. T. Harper, J. Oh, C. Parys, I. Shinzato, and A. N. Hristov, "Histidine deficiency has a negative effect on lactational performance of dairy cows," Journal of Dairy Science, vol. 100, no. 4, pp. 2784-2800, 2017.

[9] W. Kopec, A. Wiliczkiewicz, D. Jamroz et al., “Antioxidant status of turkey breast meat and blood after feeding a diet enriched with histidine," Poultry Science, vol. 95, no. 1, pp. 53-61, 2016.

[10] J. Yin, J. Ma, Y. Y. Li et al., "Branched-chain amino acids, especially of leucine and valine, mediate the protein restricted response in a piglet model," Food \& Function, vol. 11, no. 2, pp. 1304-1311, 2020.

[11] J. Yin, H. Han, Y. Li et al., "Lysine restriction affects feed intake and amino acid metabolism via gut microbiome in piglets," Cellular Physiology and Biochemistry, vol. 44, no. 5, pp. 1749-1761, 2018.

[12] S. Zhang, L. Chu, S. Qiao, X. Mao, and X. Zeng, "Effects of dietary leucine supplementation in low crude protein diets on performance, nitrogen balance, whole-body protein turnover, carcass characteristics and meat quality of finishing pigs," Animal Science Journal, vol. 87, no. 7, pp. 911-920, 2016.

[13] A. G. Wessels, H. Kluge, N. Mielenz, E. Corrent, J. Bartelt, and G. I. Stangl, "Estimation of the leucine and histidine requirements for piglets fed a low-protein diet," Animal, vol. 10, no. 11, pp. 1803-1811, 2016.

[14] Y. Li, J. Yin, H. Han et al., "Metabolic and proteomic responses to long-term protein restriction in a pig model," Journal of Agricultural and Food Chemistry, vol. 66, no. 47, pp. 1257112579, 2018.

[15] J. Yin, Y. Li, H. Han et al., "Long-term effects of lysine concentration on growth performance, intestinal microbiome, and metabolic profiles in a pig model," Food \& Function, vol. 9, no. 8, pp. 4153-4163, 2018. 
[16] M. C. B. Tossou, H. Liu, M. Bai et al., "Effect of high dietary tryptophan on intestinal morphology and tight junction protein of weaned pig," BioMed Research International, vol. 2016, Article ID 2912418, 6 pages, 2016.

[17] H. N. Liu, C. A. A. Hu, M. M. Bai et al., "Short-term supplementation of isocaloric meals with L-tryptophan affects pig growth," Amino Acids, vol. 49, no. 12, pp. 2009-2014, 2017.

[18] J. Yin, M. Liu, W. Ren et al., "Effects of dietary supplementation with glutamate and aspartate on diquat-induced oxidative stress in piglets," PLoS One, vol. 10, no. 4, article e0122893, 2015.

[19] J. Yin, W. Ren, J. Duan et al., "Dietary arginine supplementation enhances intestinal expression of SLC7A7 and SLC7A1 and ameliorates growth depression in mycotoxin-challenged pigs," Amino Acids, vol. 46, no. 4, pp. 883-892, 2014.

[20] W. D. Jiang, B. Qu, L. Feng et al., "Histidine prevents Cuinduced oxidative stress and the associated decreases in mRNA from encoding tight junction proteins in the intestine of grass carp (Ctenopharyngodon idella)," PLoS One, vol. 11, no. 6, article e0157001, 2016.

[21] J. Yin, Y. Li, H. Han et al., "Melatonin reprogramming of gut microbiota improves lipid dysmetabolism in high-fat diet-fed mice," Journal of Pineal Research, vol. 65, no. 4, article e12524, 2018.

[22] T. Kubasova, L. Davidova-Gerzova, V. Babak et al., "Effects of host genetics and environmental conditions on fecal microbiota composition of pigs," PLoS One, vol. 13, no. 8, article e0201901, 2018.

[23] H. M. Wexler, "Bacteroides: the good, the bad, and the nittygritty," Clinical Microbiology Reviews, vol. 20, no. 4, pp. 593621, 2007. 